\title{
Interactions of $S$-methylmethionine and UV-B can modify the defence mechanisms induced in maize
}

Szabolcs Rudnóy 1,*

Phone +3613722500

Email rsz@ttk.elte.hu

Imre Majláth 2

Magda Pál 2

Katalin Páldi 1

Ilona Rácz 1

Tibor Janda 2

1 Department of Plant Physiology and Molecular Plant Biology, Institute of Biology, Eötvös Loránd University (ELTE), Pázmány Peter sétány 1/C, 1117 Budapest, Hungary

2 Agricultural Institute, Centre for Agricultural Research, Hungarian Academy of Sciences, Brunszvik u. 2, 2462 Martonvásár, Hungary

\section{Abstract}

We examined the interactions of an exogenously added non-proteinogenic amino acid, S-methylmethionine (SMM) and UV-B radiation in young maize plants. We observed that exposure to UV-B light caused a substantial increase in both the phenolics and anthocyanin contents. Pretreatment with SMM also induced a slight, but statistically significant increase in the total phenol content, and was also able to accelerate the rise in the UV-B-induced anthocyanin level. Gene expression patterns indicated that the general phenylpropanoid pathway was most strongly induced by the combined effect of SMM and UV, while the anthocyanin synthesis by the sole UV-B treatment. SMM treatment and UV-B light led to a substantial increase in the activities of the antioxidant enzymes catalase (CAT), 
ascorbate peroxidase (APX) and glutathione $S$-transferase and SMM pretreatment always enhanced the effect of UV-B. While the activity of CAT showed a significant increase in UV-B- and/or SMM-treated plants, APX was stimulated only by SMM. The present results suggest that the protective mechanisms induced by UV-B radiation could be enhanced by SMM treatment and reinforce the earlier observations of priming effects of SMM so that it can contribute to our knowledge about the SMM-induced protection against various types of stressors.

\section{Keywords}

Antioxidant enzymes

Anthocyanins

Maize

Phenolics

$S$-methylmethionine

UV-B

\section{Abbreviations}

APX Ascorbate peroxidase

C3GE Cyanidin 3-glucoside equivalents

C4H Cinnamate 4-hydroxylase

CAT Catalase

CHS Chalcone synthase

CL-Cont Untreated plants grown under control light

CL-SMM Plants grown under control light and treated with

$F_{\mathrm{v}} / F_{\mathrm{m}} \quad$ Variable to maximum chlorophyll fluorescence ratio

GA Gallic acid

GAE Gallic acid equivalents

GST Glutathione $S$-transferase

oANI Ortho-anisic acid

pHBA Para-hydroxybenzoic acid

PPFD Photosynthetic photon flux density

qRT-PCR Quantitative real-time polymerase chain reaction

SA Salicylic acid

SMM S-methylmethionine 


\section{TCA Trichloroacetic acid \\ UV-Cont \\ Plants irradiated with UV but not treated with \\ $S$-methylmethionine}

UV-SMM Plants irradiated with UV and treated with S-methylmethionine

Communicated by W. Wang.

\section{Introduction}

The non-proteinogenic amino acid $S$-methylmethionine (SMM) is ubiquitous in the plant kingdom. It has an important role in the sulphur metabolism, and either directly or indirectly, in the stress and disease tolerance of plants. SMM is synthesized from methionine using $S$-adenosyl methionine as the methyl donor and is able to revert to methionine (through a transmethylation reaction involving homocysteine) in the course of the methionine cycle (Szegö et al. 2007). Consequently, it plays a role in regulating the levels of both methionine and $S$-adenosyl methionine. SMM participates in methylation processes within the cell and plays an important role in the transportation and storage of sulphur (Gigolashvili and Kopriva 2014). It is able to moderate the damaging effects of numerous stressors by enhancing the production of dimethyl sulphopropionate, which acts as an osmo- and cryoprotectant (Ogawa and Mitsuya 2012), by increasing the biosynthesis of polyamines, and by regulating ethylene production (Ko et al. 2004; Szegő et al. 2007).

Exogenous application of SMM has been shown as an effective way of inducing stress tolerance in plants. Favourable physiological effects include the increases of membrane stability, activity of enzymes that eliminate reactive oxygen species, and the amount of polyamines, which all play important role in stress defence. These effects may also explain the protective role of SMM against certain stress factors, as was earlier described in the case of cold stress (Rácz et al. 2008; Kósa et al. 2011; Páldi et al. 2014), high salinity (Ogawa and Mitsuya 2012) and virus infection (Ludmerszki et al. 2011, 2014).

A significant reduction in the stratospheric ozone layer has been revealed since the 1980s, primarily caused by the increasing emissions of anthropogenic pollutants. Consequently, the solar ultraviolet $\mathrm{B}$ radiation (UV-B, 280-320 nm wavelengths) reaching the soil surface has also increased, which is recognized as a major environmental threat (Hideg et al. 2013). High level of UV-B radiation can cause severe damage to plants; however, the 
environmental role of UV-B radiation is far broader, including the regulation of plant metabolism and morphology (Ballaré et al. 2011). Numerous studies have shown that increasing UV-B radiation results in reductions in shoot and root length, leaf area, biomass accumulation and crop yield in several crop species (Müller-Xing et al. 2014). The recently identified plant photoreceptor UVR8 (UV RESISTANT LOCUS 8) is responsible for the perception of UV-B and absolutely essential for UV-B responses, although an independent MAPK signalling pathway also contributes to UV-B tolerance in plants (González Besteiro et al. 2011). UV-B signalling pathways do not function in isolation in the intact plant, but are integrated with perception mechanisms for other environmental and endogenous signals (Heijde and Ulm 2012).

Acclimation of plants to UV-B involves the accumulation of UV-absorbing and photo-protective secondary metabolites such as phenolic compounds and anthocyanins in response to UV-B radiation exposure (Vyas et al. 2014), and may also modify the acclimation processes to other environmental factors (Gondor et al. 2014; Kovács et al. 2014). The aim of the present study was to test how an additional UV radiation, which itself does not cause serious stress symptoms, may affect certain stress-related processes and defence potential induced by SMM in young maize plants.

\section{Materials and methods}

\section{Plant growth and UV/SMM treatments}

Seeds of maize plants (Zea mays L., hybrid 'Norma') were disinfected in $3 \%$ hydrogen peroxide solution for $30 \mathrm{~min}$ and then rinsed in distilled water three times. Germination was carried out on moist filter papers at $25{ }^{\circ} \mathrm{C}$ in the dark for $72 \mathrm{~h}$. The seedlings were placed onto a stainless steel mesh ( 5 seedlings/pot) with their roots in Hoagland's nutrient solution with the following composition: $0.3125 \mathrm{mM} \mathrm{KNO}_{3}, 0.45 \mathrm{mM} \mathrm{Ca}\left(\mathrm{NO}_{3}\right)_{2}, 0.0625 \mathrm{mM}$ $\mathrm{KH}_{2} \mathrm{PO}_{4}, 0.125 \mathrm{mM} \mathrm{MgSO}{ }_{4} \cdot 7 \mathrm{H}_{2} \mathrm{O}, 11.92 \mu \mathrm{M} \mathrm{HBO}_{3}, 4.57 \mu \mathrm{M} \mathrm{MnCl}_{2} \cdot 4 \mathrm{H}_{2} \mathrm{O}$, $0.191 \mu \mathrm{M} \mathrm{ZnSO}_{4} \cdot 7 \mathrm{H}_{2} \mathrm{O}, 0.08 \mu \mathrm{M} \mathrm{CuSO}_{4} \cdot 5 \mathrm{H}_{2} \mathrm{O}, 0.024 \mu \mathrm{M}$ $\left(\mathrm{NH}_{4}\right)_{6} \mathrm{Mo}_{7} \mathrm{O}_{2} \cdot 4 \mathrm{H}_{2} \mathrm{O}, 15.02 \mu \mathrm{M} \mathrm{FeSO}{ }_{4} \cdot 7 \mathrm{H}_{2} \mathrm{O}$ and $23.04 \mu \mathrm{M} \mathrm{Na} \mathrm{N}_{2}$ EDTA $5 \mathrm{H}_{2} \mathrm{O}$.

The plants were grown in Conviron growth chambers (Controlled Environments Ltd., Winnipeg, Canada) for 21 days with $16 / 8 \mathrm{~h} \mathrm{light/dark}$ periods, $22 / 20{ }^{\circ} \mathrm{C}$ day/night temperatures, $65 / 75 \%$ day/night relative air humidity and photosynthetically active photon flux density $(\mathrm{PPFD})=250 \mu \mathrm{mol} \mathrm{m} \mathrm{s}^{-1}$ at leaf level. Half of the plants were irradiated 
with excess UV light (UV dose $350 \mu \mathrm{W} / \mathrm{cm}^{L}$ ) for $16 \mathrm{~h}$ during the whole light period measured with a portable UVLOG dosimeter (Sglux; ver. 5.08; sglux SolGel Technologies GmbH, Berlin, Germany). The UV dose at the control area was $20 \pm 5 \mu \mathrm{W} / \mathrm{cm}^{2}$. The UV-irradiated plants were separated from the control light group with a plastic sheet.

In the SMM treatment, $0.002 \mathrm{~g}^{-1} \mathrm{SMM}$ was added to the nutrient solution from the beginning of germination to the end of the growth period. The control plants continued to grow on SMM-free medium. The nutrient solution was changed every 2 days for all plants.

Four combinations of treatments were applied: plants grown under control light were either untreated (CL-Cont) or SMM-treated (CL-SMM), and similarly the plants irradiated with UV were untreated (UV-Cont) or treated with SMM (UV-SMM).

\section{Chlorophyll $a$ fluorescence induction}

The chlorophyll fluorescence induction parameters were recorded on the third fully developed leaf using a portable pulse amplitude-modulated fluorometer (PAM-2000) (Walz, Effeltrich, Germany). Measurements were carried out on days 7,14 and 21 after plants were placed in hydroponic solution. The $F_{\mathrm{v}} / F_{\mathrm{m}}$ parameter was measured after a 30-min dark adaptation period. The maximum fluorescence yield $\left(F_{\mathrm{m}}\right)$ was determined using a $0.8 \mathrm{~s}$ flash of white light $\left(\mathrm{PPFD}=3000 \mu \mathrm{mol} \mathrm{m} \mathrm{s}^{-1}\right)$. All data were evaluated with the PamWin 1.24 software (Walz). The nomenclature was based on van Kooten and Snel (1990).

\section{Gas exchange measurements}

The net photosynthesis, stomatal conductivity and transpiration rate were recorded on the third fully developed leaf using a LI-6400 infrared gas analyser (LI-COR, Lincoln, NE, USA) operated with a 6400-02 LED light source. Measurements were carried out on days 7, 14 and 21 after plants were placed in hydroponic solution. Gas exchange parameters were calculated according to von Caemmerer and Farquhar (1981).

\section{Phenolics and anthocyanin determination}

For determining the UV-absorbing phenolics and anthocyanins, measurements were carried out on days 7, 14 and 21 after plants were placed in hydroponic 
solution. $0.5 \mathrm{~g}$ fresh tissue from the second leaves or stems was extracted in methanol:water:hydrochloric acid (79:20:1, v/v) and the samples were cleared by centrifugation at $16,000 \mathrm{~g}$ for $10 \mathrm{~min}$ (Teklemariam and Blake 2004). As different phenolic compounds have different absorption characteristics within the UV range, changes in phenolic content were estimated by quantifying the absorbance of the methanol extract at the following wavelengths: 254, 270, 290, 300, and $330 \mathrm{~nm}$. A standard curve was prepared using gallic acid (GA) and the phenolic content was expressed as GA equivalents (GAE) (Teklemariam and Blake 2004). The anthocyanin content of stems was measured by spectrophotometric analysis of 20 -fold diluted methanol extracts at an absorbance of $530 \mathrm{~nm}$ (Páldi et al. 2014) and was expressed as equivalents of cyanidin 3-glucoside (C3GE) based on its molar absorptivity (Lee et al. 2005). All these measurements were carried out with a Lambda 25 UV/VIS spectrophotometer (Perkin-Elmer, Foster, CA, USA).

\section{Antioxidant enzyme activities}

The third fully developed leaves were harvested on day 21 of the experiment, after which $0.2 \mathrm{~g}$ fresh plant material was ground on quartz sand in a mortar with $2.5 \mathrm{ml}$ ice-cold $0.5 \mathrm{mM}$ Tris-HCl buffer ( $\mathrm{pH} 7.4$ ) containing $3 \mathrm{mM}$ $\mathrm{MgCl}_{2}, 5 \mathrm{mM}$ ascorbic acid and $1 \mathrm{mM}$ EDTA. The homogenate was centrifuged at $15,000 \mathrm{~g}$ for $20 \mathrm{~min}$ at $4{ }^{\circ} \mathrm{C}$. The supernatant was kept at $-20{ }^{\circ} \mathrm{C}$ until required. The glutathione $S$-transferase (GST; EC 2.5.1.18) activity was measured according to Mannervik and Guthenberg (1981), while the catalase (CAT; EC 1.11.1.6) and ascorbate peroxidase (APX; EC 1.11.1.11) activities were detected following the methods of Janda et al. (1999). Enzyme activities were determined spectrophotometrically (UV-VIS 160A, Shimadzu, Japan) and expressed in nkat $\mathrm{g}$ fresh weight $(\mathrm{FW})^{-1}$ units.

\section{Salicylic acid (SA) extraction and analysis}

Samples were collected for SA analyses 21 days after the beginning of UV-B treatment. SA was measured according to Meuwly and Métraux (1993) by grinding $1 \mathrm{~g}$ of plant tissue in liquid nitrogen in a mortar and pestle, in the presence of $0.5 \mathrm{~g}$ quartz sand. The tissue powder was transferred to a centrifugation tube and mixed with $2 \mathrm{ml}$ of $70 \%$ methanol containing $250 \mathrm{ng}$ ortho-anisic acid (oANI) (used as internal standard) and $25 \mu \mathrm{g}$ para-hydroxybenzoic acid ( $p \mathrm{HBA}$ ) (used as extraction carrier). The extract was centrifuged at $10,000 \mathrm{~g}$ for $20 \mathrm{~min}$. The pellet was resuspended in $2 \mathrm{ml}$ $90 \%$ methanol, vortexed and centrifuged as above. The methanol content was 
evaporated from the mixed supernatants at room temperature under a vacuum. After adding $1 \mathrm{ml}$ of $5 \%(\mathrm{w} / \mathrm{v})$ trichloroacetic acid (TCA) to the residual aqueous phase, the mixture was centrifuged in an Eppendorf centrifuge at $15,000 \mathrm{~g}$ for $10 \mathrm{~min}$. The supernatant was gently partitioned twice against $2 \mathrm{ml}$ of a 1:1 (v/v) mixture of ethyl acetate/cyclohexane. The upper organic layers contained the free phenolic portion. The aqueous phases containing the methanol-soluble bound phenolics were acid-hydrolysed by adding $1.3 \mathrm{ml} 8 \mathrm{~N}$ $\mathrm{HCl}$ to the aqueous phase and incubating for $60 \mathrm{~min}$ at $80{ }^{\circ} \mathrm{C}$ before partitioning twice as above. Just prior to the HPLC analysis, the samples were resuspended in $1000 \mu \mathrm{l}$ of the HPLC starting mobile phase. After separation on a reverse phase column $(\mathrm{ABZ}+, 150 \times 4.5 \mathrm{~mm}, 5 \mu \mathrm{m}$, Supelco, Bellefonte, USA), SA was quantified fluorimetrically (W474 scanning fluorescence detector, Waters, USA), with the excitation at $305 \mathrm{~nm}$ and emission at $407 \mathrm{~nm}$.

\section{Gene expression}

Leaf tissue mRNA was isolated with GenoPrep mRNA beads (GenoVision, Oslo, Norway) from the second leaves according to the manufacturer's instructions, on days 7, 14 and 21 after plants were placed in hydroponic solution. Extracted mRNA was treated with RNase-free DNase I. The first cDNA strand was synthesized from $0.5 \mu \mathrm{g}$ of mRNA using a RevertAid First Strand cDNA synthesis kit (Thermo Scientific, Rockford, IL, USA) and the quantitative real-time polymerase chain reaction (qRT-PCR) was performed using an ABI PRISM ${ }^{\circledR} 7000$ sequence detection system (Perkin-Elmer) with Power SYBR ${ }^{\circledR}$ Green PCR master mix (Life Technologies, Carlsbad, CA, USA). The thermal cycling conditions for qRT-PCR consisted of 40 cycles of $95{ }^{\circ} \mathrm{C}$ for $15 \mathrm{~s}, 60{ }^{\circ} \mathrm{C}$ for $15 \mathrm{~s}$, and $72{ }^{\circ} \mathrm{C}$ for $30 \mathrm{~s}$. A maize actin gene and the membrane protein gene PB1A10.07c (MEP) were included in the assays as internal controls for normalizing the variations in the cDNA amounts used (Manoli et al. 2012). The geometric mean of the internal control data was applied for normalization. The genes of interest were cinnamate 4-hydroxylase $(\mathrm{C} 4 \mathrm{H})$, chalcone synthase (CHS) and glutathione S-transferase-1 (GST-1) (Table 1). The relative changes in gene expression were quantified according to the $2^{-} \quad \mathrm{C}_{\mathrm{t}}$ method of Schmittgen and Livak (2008).

\section{Table 1}

qRT-PCR primers used for analysing gene expression changes 


\begin{tabular}{|c|c|c|c|}
\hline Gene & $\begin{array}{l}\text { Accession } \\
\text { number }\end{array}$ & $\begin{array}{l}\text { Forward and reverse primer } \\
\text { sequences }\left(5^{\prime}-3^{\prime}\right)\end{array}$ & $\begin{array}{l}\text { Amplicon } \\
\text { length (bp) }\end{array}$ \\
\hline Actin & $\mathrm{J} 01238^{\mathrm{a}}$ & $\begin{array}{l}\text { CGCTAGTGGGCGAACAACT and } \\
\text { CGCATGAGGAAGTGTGTATCC }\end{array}$ & 92 \\
\hline$M E P$ & AY105120.1 & $\begin{array}{l}\text { TTCCTCATGTTCTTCGTGCC and } \\
\text { CAGTTCTCATTCCATCCGTG }\end{array}$ & 130 \\
\hline $\mathrm{C} 4 \mathrm{H}$ & BT039467 & $\begin{array}{l}\text { GCGGAAGAAGGTGATGGCTC and } \\
\text { AGAGGAGGTTGTCGTGGTTGAT }\end{array}$ & 99 \\
\hline CHS & NM_001148774 ${ }^{\mathrm{a}}$ & $\begin{array}{l}\text { GCCGACTACCCGGACTACTA and } \\
\text { CTTGCGGATCATCGACTTGT }\end{array}$ & 102 \\
\hline GST-1 & $\mathrm{X} 06754^{\mathrm{a}}$ & $\begin{array}{l}\text { TGCTCTACAGGATGGTGACT and } \\
\text { CTCCACCTCGATCCAAACAT }\end{array}$ & 139 \\
\hline
\end{tabular}

\section{Statistical analyses}

The whole experiments were repeated three times, and a representative set of experiments is presented here. Differences in the data were analysed by one-way ANOVA with $P<0.05$ indicating statistical significance. Data represent the mean of four parallel values. Duncan's multiple-range test was used to detect significant differences between groups.

\section{Results}

\section{Effects of SMM treatment and UV-B on the photosynthetic responses}

The maize hybrid 'Norma' grown in hydroponics was exposed to UV-B light during the growth period for 3 weeks. Some of the plants were treated with SMM, which was added directly to the hydroponic solution. This UV-B treatment did not significantly affect the gas exchange parameters in hybrid 'Norma' (Fig. 1). Under control conditions, the SMM treatment caused a slight but statistically significant decrease in the stomatal conductivity and transpiration after the second week of the experiment. Ageing also reduced the stomatal opening; however, these changes did not significantly affect the net photosynthesis. Furthermore, neither of the treatments caused significant changes in either the maximum or the actual quantum yield of Photosystem II represented by the $F_{\mathrm{v}} / F_{\mathrm{m}}$ and $\left(\mathrm{F}_{\mathrm{m}}-\mathrm{F}_{\mathrm{s}}\right) / \mathrm{F}_{\mathrm{m}}$ chlorophyll $a$ fluorescence induction parameters, respectively (data not shown). 
Fig. 1

Effects of UV-B and SMM treatment on the net photosynthesis, stomatal conductance and transpiration rate (CL-Cont control plants, $C L-S M M$ control light and SMM treatment, UV-Cont UV-B exposure, UV-SMM UV-B exposure and SMM treatment). Numbers days after germination. Values are mean $\pm \mathrm{SD}$ $(n=4)$. Letters significant differences between treatments $(P<0.05$; Duncan's multiple-range test)
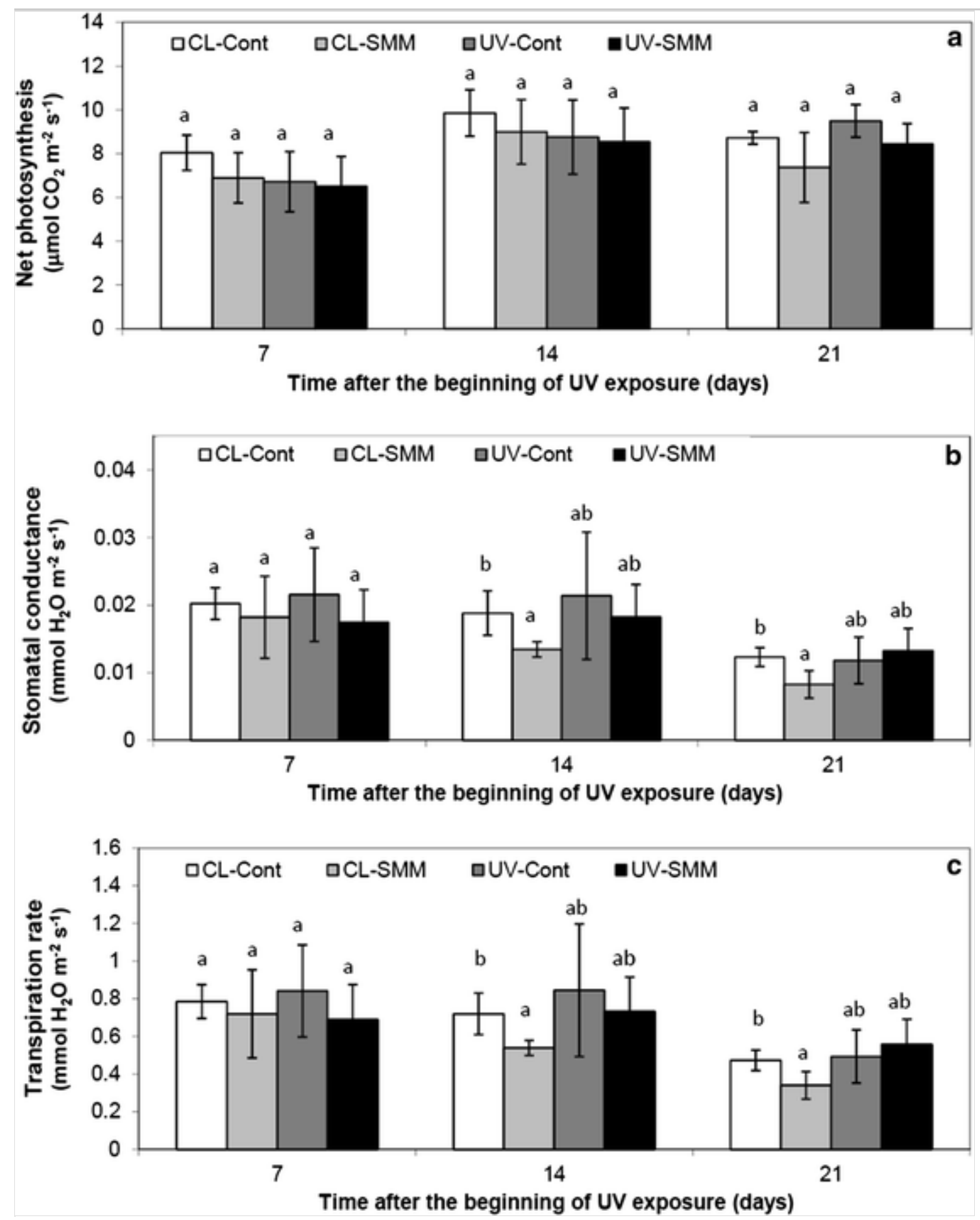

Changes in the phenolics and anthocyanin contents in response to SMM and UV-B treatments 
Phenolic compounds were more abundant in the leaves, while anthocyanins were more easily characterized from the stem, where they are usually perceptible to the naked eye. The level of total phenolics in the leaves significantly increased in UV-B-stressed plants during the 3 weeks of measurements, and SMM did not affect this change (Fig. 2 a). The increasing effect of SMM treatment under normal light conditions developed at a slower rate, while the control values did not change with ageing. Changes in the stem were similar: UV-B exposure caused the greatest increase, and SMM co-treatment only tempered this increase remarkably in the first week of measurements (Fig. 2 b). Without supplementary UV-B radiation, the SMM treatment only increased the level of phenolics to a slight extent. All the treatments showed a continuous decrease in the total phenolics in the stem with ageing.

\section{Fig. 2}

Effects of UV-B and SMM treatment on phenolics content of maize seedlings in a leaves and b stem. CL-Cont control plants, CL-SMM control light and SMM treatment, UV-Cont UV-B exposure, UV-SMM UV-B exposure and SMM treatment. Values are mean $\pm \mathrm{SD}(n=4)$. Letters significant differences between treatments $(P<0.05$; Duncan's multiple-range test $)$ 

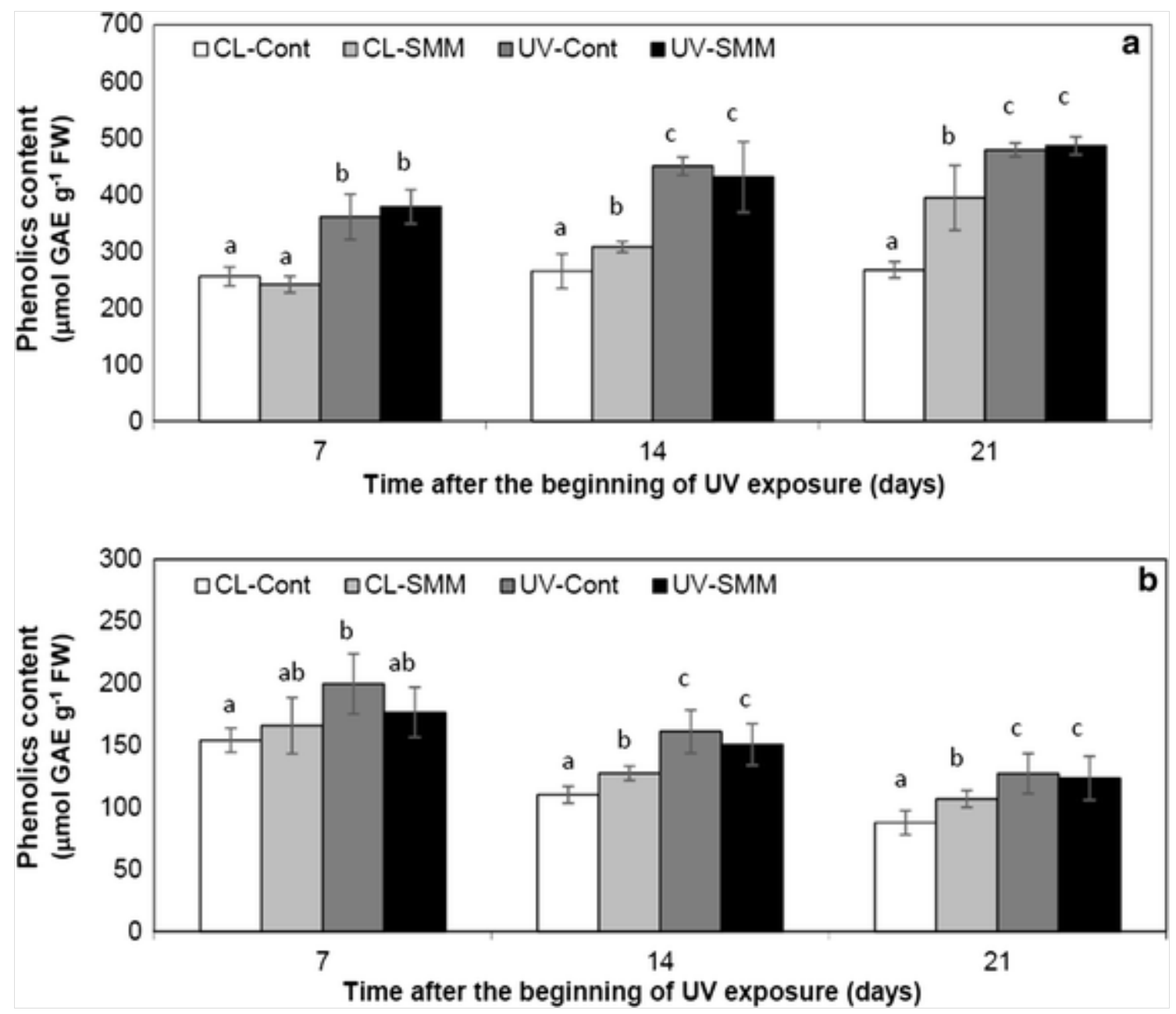

The anthocyanin levels in the leaves increased with ageing in all treatments except the control (Fig. 3 a). However, under control light conditions, SMM only caused a slight change in the quantity of anthocyanins. UV-B caused a slight but significant increase in the first 2 weeks of the experiment and a pronounced $\sim 2.26$-fold rise in the third week. When SMM-treated plants were exposed to UV-B radiation, the increase in the anthocyanin content appeared earlier and was more intense than in UV-stressed plants without SMM treatment in the first week. In the second and third weeks, this value was equal to or less than the value recorded for UV-stressed plants without SMM. The anthocyanin levels in the stem showed a similar pattern, responding to SMM treatment with a slight difference under normal illumination, to UV-B exposure with a continuous increase and to the combination of the two treatments with an earlier and stronger response (Fig. $3 \mathrm{~b}$ ).

Fig. 3

Effects of UV-B and SMM treatment on anthocyanin content of maize seedlings in a leaves and b stem. CL-Cont control plants, CL-SMM control light and SMM treatment, $U V$-Cont UV-B exposure, UV-SMM UV-B exposure and SMM treatment. Values are mean $\pm \mathrm{SD}(n=4)$. Letters significant differences between 
treatments $(P<0.05$; Duncan's multiple-range test $)$
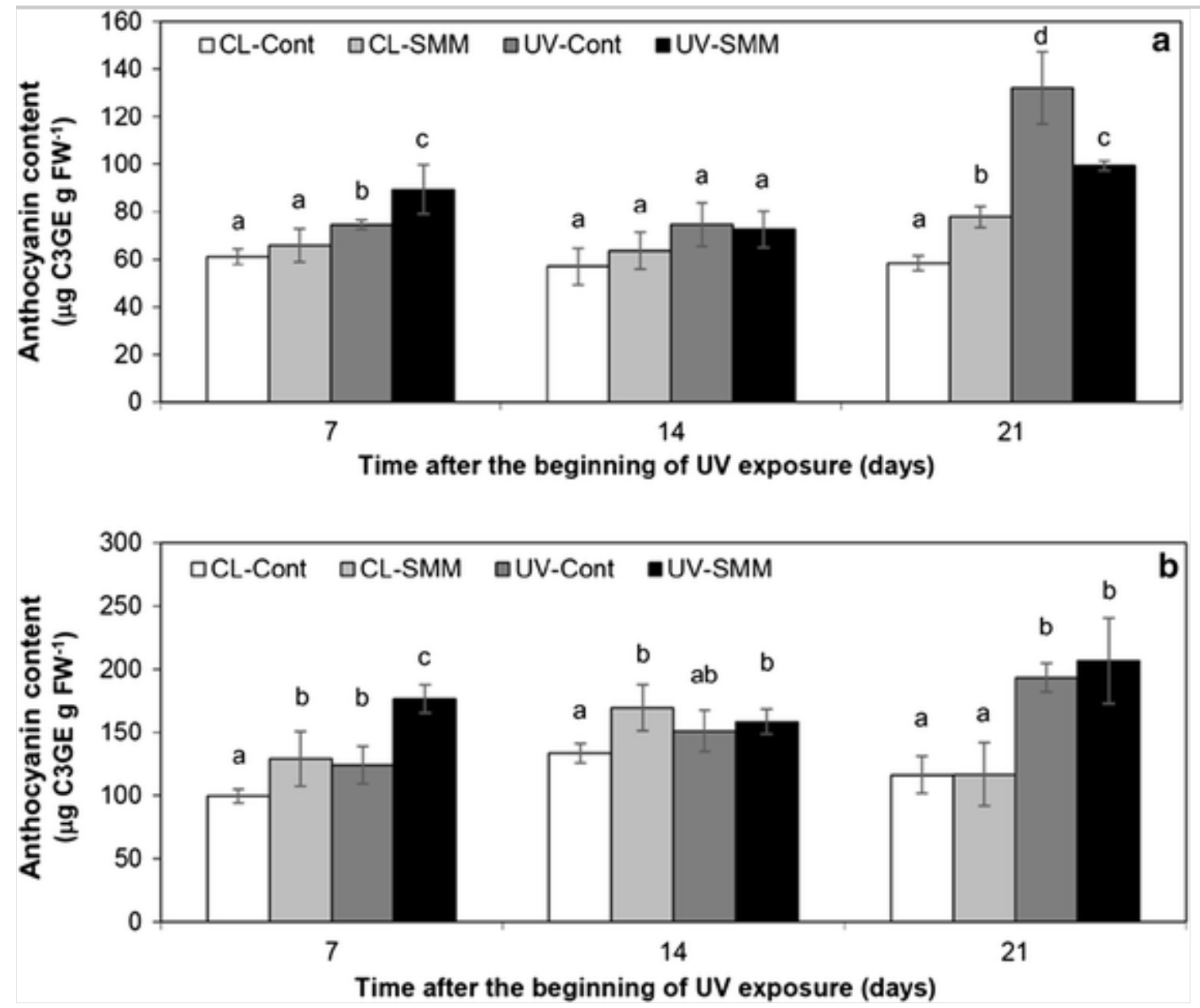

\section{Changes in the antioxidant activities after SMM and UV-B treatments}

The antioxidant enzyme activities were significantly affected by the UV-B and/or SMM treatments. In general, after 3 weeks, the SMM treatment led to a substantial increase in the activities of the antioxidant enzymes tested, namely GST, CAT, and APX (Fig. 4). The highest changes occurred in plants treated with SMM alone; however, exposure to UV-B reduced the effects of SMM. UV light substantially increased the activity of CAT, but did not significantly affect the activity of GST under control conditions. However, UV-B was able to compensate for the SMM-induced increase in this enzyme. The activity of APX was not substantially affected by UV-B but SMM enhanced the activity in both of the lighting conditions. The quantity of the signal transducer salicylic acid (SA) was also determined; however, under the present experimental conditions, neither SMM nor UV-B caused significant changes in the endogenous levels of either free or bound SA (Table 2).

Fig. 4 
Effects of UV-B and SMM treatment on day 21 of the experiment on a glutathione $S$-transferase, b catalase and c ascorbate peroxidase activity. CL-Cont control plants, CL-SMM control light and SMM treatment, UV-Cont UV-B exposure, UV-SMM UV-B exposure and SMM treatment. Values are mean $\pm \mathrm{SD}(n=4)$. Letters significant differences between treatments $(P<0.05$; Duncan's multiple-range test)
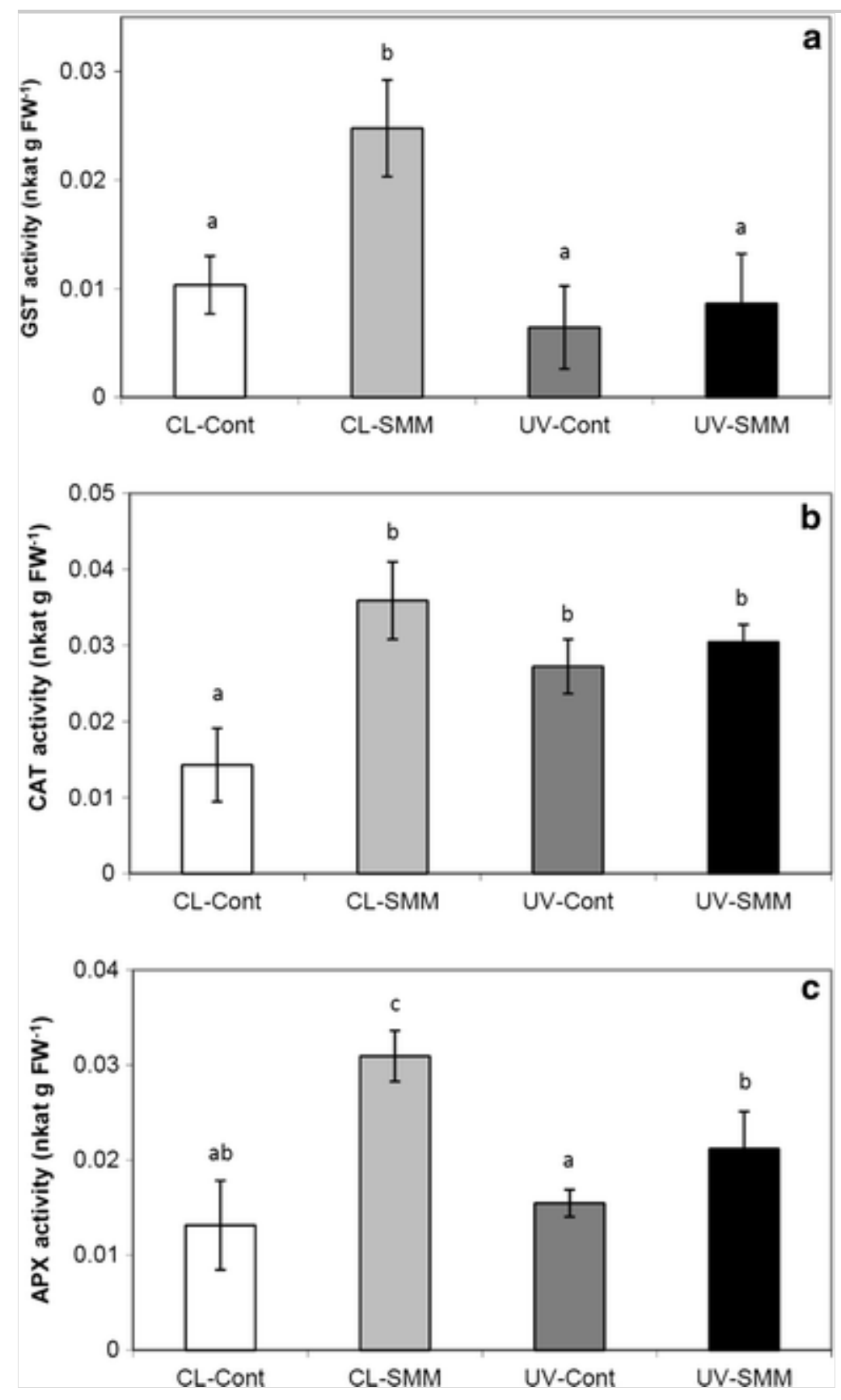

Table 2

Effects of SMM and/or UV-B treatment on the SA contents (ng g ${ }^{-1} \mathrm{FW}$ ) in maize plants

\begin{tabular}{|l|l|l|}
\hline & Free SA & Bound SA \\
\hline Control & $26.7 \pm 17.0$ & $156.1 \pm 27.3$ \\
\hline
\end{tabular}




\section{Free SA}

UV-B

SMM

$\mathrm{SMM}+\mathrm{UV}-\mathrm{B}$
$17.5 \pm 7.1^{\mathrm{ns}}$

$15.3 \pm 11.0^{\mathrm{ns}}$

$19.2 \pm 7.0^{\mathrm{ns}}$

\section{Bound SA}

$171.8 \pm 43.6^{\mathrm{ns}}$

$204.5 \pm 98.6^{\mathrm{ns}}$

$154.3 \pm 38.0^{\mathrm{ns}}$

Values are mean $\pm \operatorname{SD}(n=4)$

ns no significant difference between the treated plants and the controls

\section{Changes in gene expression induced by SMM and UV-B treatments}

Quantitative real-time PCR analysis was carried out to investigate changes in the expression of the $C 4 H$, CHS and GST-1 genes after UV-B exposure, SMM treatment and their combination. The $C_{t}$ method was used for the calculations. The quantity of $\mathrm{C} 4 \mathrm{H}$ transcripts dropped significantly in the first week, while culminating in the second week in all the treatment groups (Fig. 5 a). SMM-treated plants which were also exposed to UV-B produced the highest rate of increase, with a little more than twofold rise; however, their $\mathrm{C} 4 \mathrm{H}$ expression returned to the control level in the third week. UV-B without SMM caused a 47 and $32 \%$ increase in the second and third week, respectively. Under normal light conditions, SMM tended to decrease $C 4 H$ expression.

\section{Fig. 5}

Relative transcription level of the phenylpropanoid biosynthetic pathway genes a $C 4 H$ and $\mathbf{b} C H S$ and the universal defence gene c GST-1 in maize seedlings exposed to UV-B radiation and treated with SMM. Data are shown as a \%, compared to control plants (100\%). CL-Cont control plants, CL-SMM control light and SMM treatment, UV-Cont UV-B exposure, UV-SMM UV-B exposure and SMM treatment. Relative gene expression was normalized by comparing the $\Delta \Delta \mathrm{C}_{\mathrm{t}}$ values of genes of interest and two internal controls (see the text). Values are mean $\pm \operatorname{SD}(n=4)$. Letters significant differences between treatments $(P<0.05$; Duncan's multiple-range test $)$ 

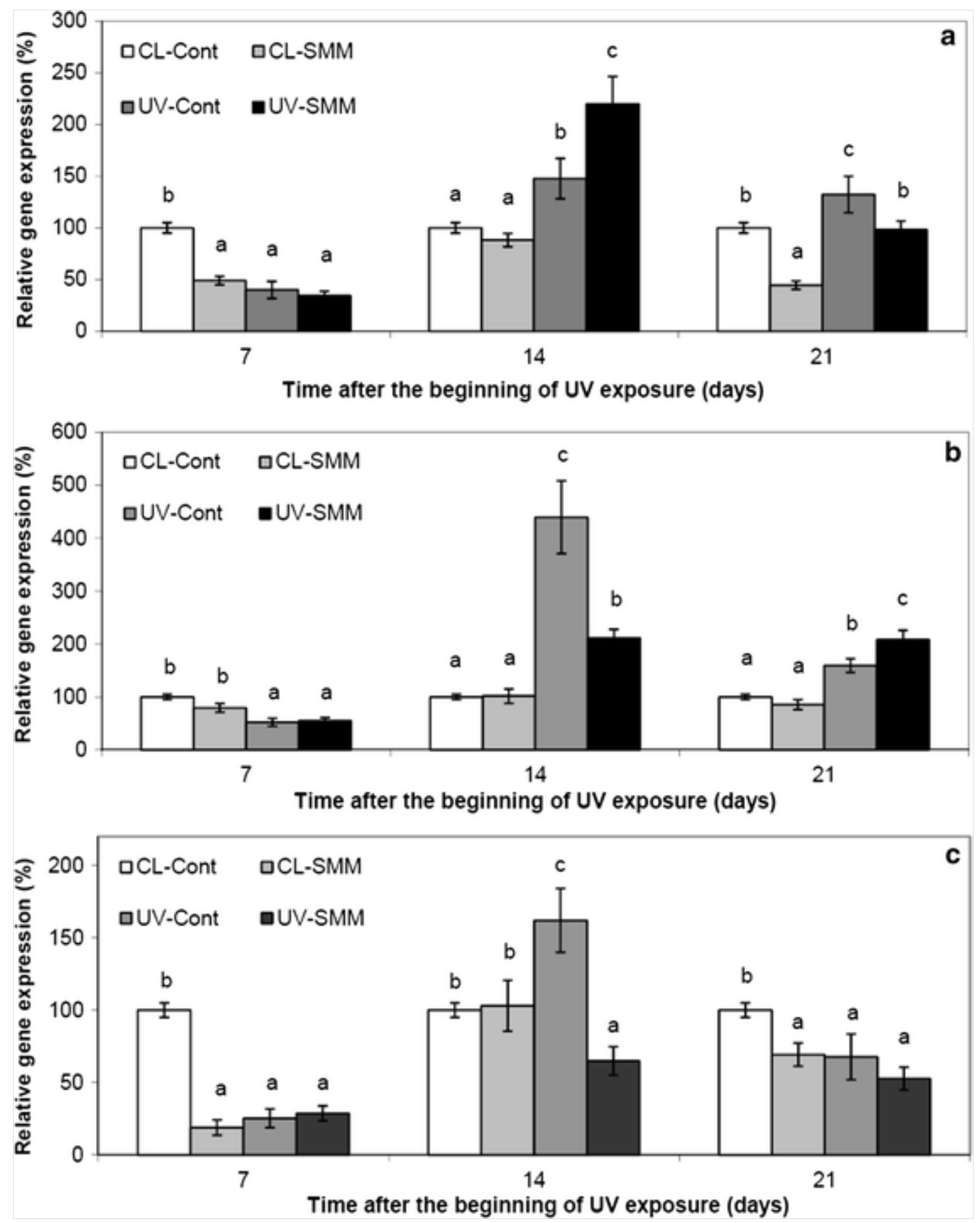

Changes in the expression of CHS were not modified by SMM without UV-B stress. UV raised the CHS transcription rate to more than $400 \%$ of the control in the second week, which was tempered by the additional SMM treatment to about $200 \%$. The latter increase persisted in the third week in contrast to the effect of UV stress without SMM treatment, where the CHS transcription level decreased to $160 \%$ of the control (Fig. $5 \mathrm{~b}$ ).

Gene expression experiments on GST-1 revealed a similar pattern in the first 2 weeks to that of $C H S$, though with more moderate changes. All the treatments strongly decreased the transcription of the GST-1 gene in the first 
week to $19-29 \%$ of the control and almost all the values remained close to or below the control throughout the experiment, the only exception being UV-B irradiation in the second week, which induced a $62 \%$ increase in GST-1 gene expression (Fig. 5c).

\section{Discussion}

Photosynthesis is one of the main targets of several types of stressors. The application of SMM for 2 weeks led to a slight decrease in the stomatal conductivity, leading to a similar decrease in the transpiration rate; however, it was not manifested as significantly lower photosynthetic activity. UV-B radiation has been demonstrated to influence photosynthetic processes via multiple sites of inhibition (Jenkins 2009), including changes in the photosynthetic electron transport processes and in mechanisms related to carbon fixation. The down-regulation of nuclear- or chloroplast-encoded photosynthetic genes may also cause a substantial loss of protein content and activity, leading to decreased photosynthetic functioning. However, in the present work, the exposure of maize plants to UV-B radiation did not significantly reduce the net photosynthetic activity or the electron transport processes characterized by either the maximum or the actual quantum yield of PS II, indicating that the UV-B dose used in the experiment did not act as a substantially harmful stressor in young maize plants.

Although the photosynthetic processes were not substantially affected by UV-B or SMM, changes in several stress-related acclimation mechanisms could be detected in plants treated with SMM or UV-B alone or in combination. The accumulation of flavonoids and related phenolics has often been proposed as an adaptive mechanism to prevent radiation from reaching the mesophyll, and anthocyanins have been found to mitigate photooxidative injury in leaves by shielding the chloroplasts from excess light and by scavenging ROS (Zhang et al. 2012). It has been shown that anthocyanin acts as a protective agent preventing high levels of solar radiation from damaging the photosynthetic machinery. Plants may up-regulate anthocyanin biosynthesis in response to light stimulus (Cominelli et al. 2008). In the present experiments, exposure to moderate UV-B light, which did not significantly affect the photosynthetic capacity, caused a substantial increase in both the phenolics and anthocyanin contents in young maize plants. Pretreatment with SMM also induced a slight, but statistically significant increase in the total phenol content of plants in normal light 14 and 21 days after the beginning of the experiment, and was also able to accelerate the rise 
in the UV-B-induced anthocyanin level under UV-B conditions, as observed in plants exposed to UV-B for 1 week. SMM can stimulate the phenylpropanoid pathway in the case of cold stress too. Páldi et al. (2014) showed that the expression of $\mathrm{C} 4 \mathrm{H}$ and $\mathrm{CHS}$ genes of the pathway is increased by the low temperature stress but both genes could be further activated by SMM. Upregulating effects of cold and SMM so seem to be additive, substantially contributing the faster and stronger reaction and the priming character of SMM. We can see similar interaction in the UV-B-exposed and SMM-pretreated plants (Figs. 2, 3, 5).

It has been shown in Arabidopsis plants that ROS of different biochemical origin together with various other signalling components acts along parallel pathways to mediate the responses of specific genes to UV-B radiation in the early phase of acclimation (Jenkins 2009). The modification of antioxidant enzymes in the monocot maize plants by UV-B light was observed in the present study, while SMM pretreatment also had an influence on the activity of certain antioxidant enzymes. CAT, which is responsible for the decomposition of hydrogen peroxide to water and oxygen, and thereby playing a central role in the protection of cells against oxidative damage, showed a significant increase in UV-B- and/or SMM-treated plants. The other antioxidant enzyme APX only increased in SMM-treated plants, not after exposure to UV-B. Interestingly enough, in contrast to these antioxidant enzymes, the GST activity was reduced by UV-B in maize leaves. However, due to the low initial value, this decrease was not statistically significant in the control plants; it was drastically lower in the SMM-treated ones. Plant GSTs are a super-family of selectively stress-inducible proteins of divergent sequence but conserved structure, which selectively bind GSH (Dixon et al. 2010 ). The main role of GSTs is to conjugate xenobiotics to glutathione and thereby detoxify cellular environments; they are also capable of binding other ligands with important cell signalling functions, such as the kinases involved in the mitogen-activated protein kinase pathway that regulates cell proliferation and death, thus preventing the kinase from carrying out its role in facilitating the signalling cascade (Laborde 2010). It was also recently shown that certain phenolics, such as quercetin-4'-glucoside, may function as a physiological inhibitor of certain GSTs in the onion bulb (Rohman et al. 2009, 2010). Therefore, the reduced total GST activity in UV-B-treated maize plants could be partly explained by the decreased gene expression level, and by a possible direct inhibition due to the increased phenolic content. However, the explanation of changes induced by SMM in GST activity is still 
unknown.

Salicylic acid is a component of the signal transduction pathway that leads to the regulation of acclimation processes under stress conditions in plants (Janda et al. 2014; Kovács et al. 2014). In an earlier study, changes in ROS and salicylic acid resulting from extreme and prolonged UV-B treatment were observed in Arabidopsis (Surplus et al. 1998). However, in the present case, the exposure of maize to UV-B did not cause significant changes in the SA levels, so the changes observed in the antioxidant enzymes were probably due to an SA-independent signalling pathway.

$\mathrm{C} 4 \mathrm{H}$ catalyses the second reaction in the stress-induced phenylpropanoid pathway (Ambrosone et al. 2013 ) and is one of the most studied cytochrome P450 enzymes in plants, exhibiting a key role in the synthesis of the phenylpropanoid polymer lignin (Weng and Chapple 2010). In Salvia miltiorrhiza, the overexpression of $\mathrm{C} 4 \mathrm{H}$ activated two parallel pathways of rosmarinic acid biosynthesis, increasing the trans-cinnamic acid and 4-coumaric acid accumulation in the phenylpropanoid pathway and the L-tyrosine and 4-hydroxyphenylpyruvic acid in the tyrosine-derived pathway, thus leading to large quantities of the end-products, phenolic acids (Xiao et al. 2011). Although the expression of $C 4 H$ was suppressed in all of our treated plants in the first week, significant increase was observed later, most remarkably 14 days after the beginning of UV-B exposure in UV-SMM plants, indicating a strong response of the general phenylpropanoid biosynthetic pathway to the combined effects of UV and SMM. This is consistent with the effect of SMM applied prior to a cold stress in maize and indicates the priming effect of SMM pretreatment enhancing the defensive reactions of plants against environmental challenges such as UV-B and cold (Kósa et al. 2011; Páldi et al. 2014).

CHS is the first enzyme in the flavonoid-specific branch of the phenylpropanoid biosynthesis pathway. CHS expression is triggered by various environmental and endogenous stimuli, including UV or blue light, and this can be seen as a protective mechanism as it promotes the accumulation of UV-absorbing flavonoids in the epidermis (Jenkins 2009). Under the environmental conditions used in the present experiment, the enhanced expression of the gene encoding CHS was clearly demonstrated after the second week. The effect of SMM was not consistent: the UV-induced induction was reduced by SMM pretreatment after the second week, but was higher after longer exposure. Since the regulation of CHS by UV-B is quite 
complex, involving several other components such as the phytochrome system or certain cryptochromes, it can be concluded that the identification of all the elements playing a role in the interaction between UV-B signalling and SMM will be a major challenge for the future.

In conclusion, the present results suggest that SMM treatment, although it may act as a mild stress factor, also induces priming, resulting in the increase of certain phenolic compounds, such as anthocyanins, and the activity of certain antioxidant enzymes, such as APX. UV-B radiation also induces protective mechanisms, such as the induction of flavonoid biosynthesis, or alterations in the antioxidant system before the appearance of stress symptoms in maize. Pretreatment of seeds of young maize plants with SMM and exposure to non-lethal UV-B may either accelerate, as in the case of, for example, the induction of anthocyanins; or compensate each other, as it was found at certain antioxidant enzymes, depending on the acclimation mechanism and the duration of the UV-B.

Author contribution statement S. Rudnóy, I. Rácz and T. Janda have made substantial contribution to work conception and experimental design. I. Majláth was responsible for growth of the plants, UV-B application and physiological analysis. M. Pál and T. Janda performed enzymatic measurements and salicylic acid analysis. K. Páldi and S. Rudnóy conducted the experiments in gene expression. S. Rudnóy and T. Janda wrote the manuscript and M. Pál and I. Rácz contributed to manuscript improvement. All authors read and approved the final manuscript.

\section{Acknowledgments}

The authors thank Dr. Demeter Lásztity for all his help and advice, Györgyi Balogh for her technical assistance and Barbara Harasztos for revising the manuscript linguistically. Thanks are due to Csaba Marton (MTA ATK Department of Maize Breeding) for providing the maize seeds. This work was funded by a grant from the Hungarian National Scientific Research Fund (OTKA K108834).

\section{Conflict of interest}

The authors declare that they have no conflict of interest.

\section{References}


Ambrosone A, Di Giacomo M, Leone A, Grillo S, Costa A (2013)

Identification of early induced genes upon water deficit in potato cell cultures by cDNA-AFLP. J Plant Res 126:169-178

Ballaré CL, Caldwell MM, Flint SD, Robinson SA, Bornman JF (2011) Effects of solar ultraviolet radiation on terrestrial ecosystems. Patterns, mechanisms, and interactions with climate change. Photochem Photobiol Sci 10:226-241

Cominelli E, Gusmaroli G, Allegra D, Galbiati M, Wade HK, Jenkins GI, Tonelli C (2008) Expression analysis of anthocyanin regulatory genes in response to different light qualities in Arabidopsis thaliana. J Plant Physiol 165:886-894

Dixon DP, Skipsey M, Edwards R (2010) Roles for glutathione transferases in plant secondary metabolism. Phytochemistry 71:338-350

Gigolashvili T, Kopriva S (2014) Transporters in plant sulfur metabolism. Front Plant Sci 5:442. doi:10.3389/fpls.2014.00442

Gondor OK, Szalai G, Kovács V, Janda T, Pál M (2014) Impact of UV-B on drought- or cadmium-induced changes in the fatty acid composition of membrane lipid fractions in wheat. Ecotox Environ Safety 108:129-134

González Besteiro MA, Bartels S, Albert A, Ulm R (2011) Arabidopsis MAP kinase phosphatase 1 and its target MAP kinases 3 and 6 antagonistically determine UV-B stress tolerance, independent of the UVR8 photoreceptor pathway. Plant J 68:727-737

Heijde M, Ulm R (2012) UV-B photoreceptor-mediated signalling in plants. Trends Plant Sci 17:230-237

Hideg É, Jansen MAK, Strid Å (2013) UV-B exposure, ROS, and stress: inseparable companions or loosely linked associates? Trends Plant Sci 18:107-115

Janda T, Szalai G, Tari I, Páldi E (1999) Hydroponic treatment with salicylic acid decreases the effect of chilling injury in maize (Zea mays L.) plants. Planta 208:175-180 
Janda T, Gondor OK, Yordanova R, Szalai G, Pál M (2014) Salicylic acid and photosynthesis: signalling and effects. Acta Physiol Plant $36: 2537-2546$

Jenkins GI (2009) Signal transduction in responses to UV-B radiation. Annu Rev Plant Biol 60:407-431

Ko S, Eliot AC, Kirsch JF (2004) S-methylmethionine is both a substrate and an inactivator of 1-aminocyclopropane-1-carboxylate synthase. Arch Biochem Biophys 421:85-90

Kósa E, Szegő D, Horváth E, Rácz I, Szigeti Z, Lásztity D, Páldi E (2011) Effect of $S$-methylmethionine on the photosynthesis in maize at different chilling temperatures. Cent Eur J Biol 6:75-83

Kovács V, Gondor OK, Szalai G, Majláth I, Janda T, Pál M (2014) UV-B radiation modifies the acclimation processes to drought or cadmium in wheat. Env Exp Bot 100:122-131

Laborde E (2010) Glutathione transferases as mediators of signaling pathways involved in cell proliferation and cell death. Cell Death Differ $17: 1373-1380$

Lee J, Durst RW, Wrolstad RE (2005) Determination of total monomeric anthocyanin pigment content of fruit juices, beverages, natural colorants, and wines by the $\mathrm{pH}$ differential method: collaborative study. J AOAC Int 88:1269-1278

Ludmerszki E, Rudnóy S, Almási A, Szigeti Z, Rácz I (2011) The beneficial effects of $S$-methyl-methionine in maize in the case of Maize dwarf mosaic virus infection. Acta Biol Szegediensis 55:109-112

Ludmerszki E, Rácz I, Rudnóy S (2014) S-methylmethionine alters gene expression of candidate genes in Maize dwarf mosaic virus infected and drought stressed maize plants. Acta Biol Szegediensis 58:1-5

Mannervik B, Guthenberg C (1981) Glutathione transferase (human placenta). Methods Enzymol 77:231-235

Manoli A, Sturaro A, Trevisan S, Quaggiotti S, Nonis A (2012) Evaluation 
of candidate reference genes for qPCR in maize. J Plant Physiol 169:807-815

Meuwly P, Métraux JP (1993) Ortho-anisic acid as internal standard for the simultaneous quantitation of salicylic acid and its putative biosynthetic precursors in cucumber leaves. Anal Biochem 214:500-505

Müller-Xing R, Xing Q, Goodrich J (2014) Footprints of the sun: memory of UV and light stress in plants. Front Plant Sci 5:474.

doi:10.3389/fpls.2014.00474

Ogawa S, Mitsuya S (2012) S-methylmethionine is involved in the salinity tolerance of Arabidopsis thaliana plants at germination and early growth stages. Physiol Plant 144:13-19

Páldi K, Rácz I, Szigeti Z, Rudnóy S (2014) S-methylmethionine alleviates the cold stress by protection of the photosynthetic apparatus and stimulation of the phenylpropanoid pathway. Biol Plant 58:189-194

Rácz I, Páldi E, Szalai G, Janda T, Pál M, Lásztity D (2008)

$S$-methylmethionine reduces cell membrane damage in higher plants exposed to low-temperature stress. J Plant Physiol 165:1483-1490

Rohman MM, Hossain MD, Suzuki T, Takada G, Fujita M (2009) Quercetin-40-glucoside: a physiological inhibitor of the activities of dominant glutathione S-transferases in onion (Allium cepa L.) bulb. Acta Physiol Plant 31:301-309

Rohman MM, Hossain MD, Fujita M (2010) Levels of a dominant glutathione $S$-transferase in onion bulbs have a seasonal relationship with physiological inhibitors. Aust J Crop Sci 4:55-62

Schmittgen TD, Livak KJ (2008) Analyzing real-time PCR data by the comparative $\mathrm{C}_{\mathrm{T}}$ method. Nat Protoc 3:1101-1108

Surplus SL, Jordan BR, Murphy AM, Carr JP, Thomas B, A-H-Mackerness S (1998) UV-B induced response in Arabidopsis thaliana: role of salicylic acid and ROS in the regulation of transcripts and acidic PR proteins. Plant Cell Environ 21:685-694 
Szegő D, Kósa E, Horváth E (2007) Role of S-methylmethionine in the plant metabolism. Acta Agron Hung 55:491-508

Teklemariam TA, Blake TJ (2004) Phenylalanine ammonia-lyase-induced freezing tolerance in jack pine (Pinus banksiana) seedlings treated with low, ambient levels of ultraviolet-B radiation. Physiol Plant 122:244-253

van Kooten O, Snel JHF (1990) The use of chlorophyll fluorescence nomenclature in plant stress physiology. Photosynth Res 25:147-150

von Caemmerer S, Farquhar GD (1981) Some relationships between the biochemistry of photosynthesis and the gas exchange of leaves. Planta $153: 376-387$

Vyas P, Haque I, Kumar M, Mukhopadhyay K (2014) Photocontrol of differential gene expression and alterations in foliar anthocyanin accumulation: a comparative study using red and green forma Ocimum tenuiflorum. Acta Physiol Plant 36:2091-2102

Weng J-K, Chapple C (2010) The origin and evolution of lignin biosynthesis. New Phytol 187:273-285

Xiao Y, Zhang L, Gao S, Saechao S, Di P, Chen J, Chen W (2011) The c4h, tat, hppr and hppd genes prompted engineering of rosmarinic acid biosynthetic pathway in Salvia miltiorrhiza hairy root cultures. PLoS ONE 6(12):e29713. doi:10.1371/journal.pone.0029713

Zhang Q, Su L-J, Chen J-W, Zeng X-Q, Sun B-Y, Peng C-L (2012) The antioxidative role of anthocyanins in Arabidopsis under high-irradiance. Biol Plant 56:97-104 